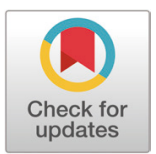

Received: Feb 18, 2020

Revised: Mar 25, 2020

Accepted: Mar 26, 2020

*Corresponding author JinSoo Kim

College of Animal Life Sciences, Kangwon National University, Chuncheon 24341, Korea.

Tel: +82-33-250-8614

E-mail: kjs896@kangwon.ac.kr

Copyright $\odot 2020$ Korean Society of

Animal Sciences and Technology.

This is an Open Access article distributed under the terms of the Creative Commons Attribution Non-Commercial License (http:// creativecommons.org/licenses/by$\mathrm{nc} / 4.0 /$ ) which permits unrestricted non-commercial use, distribution, and reproduction in any medium, provided the original work is properly cited.

ORCID

HanSeo Ko

https://orcid.org/0000-0001-9475-2761

YoungHwa Kim

https://orcid.org/0000-0002-9850-8894

JinSoo Kim

https://orcid.org/0000-0002-9518-7917

Competing interests

No potential conflict of interest relevant to this article was reported

Funding sources

This work was supported by

Cooperative Research Program for Agriculture Science and Technology

Development (Project No.

PJ014485032020), Rural Development

Administration, Korea.

\section{The produced mealworm meal through organic wastes as a sustainable protein source for weanling pigs}

\author{
HanSeo Ko ${ }^{1}$, YoungHwa Kim ${ }^{2}$ and JinSoo Kim ${ }^{1 *}$ \\ ${ }^{1}$ College of Animal Life Sciences, Kangwon National University, Chuncheon 24341, Korea \\ ${ }^{2}$ Swine Division, National Institute of Animal Science, Rural Development Administration, Cheonan 31000, \\ Korea
}

\begin{abstract}
This study was designed to evaluate the influence of dietary supplementation of Tenebrio molitor larvae (TM) as an alternative source of protein to fish meal on growth response, retention of nutrient, hematological factors, immune system, and intestinal integrity in weaned pigs. A total of 180 weanling pigs (initial bodyweight of $6.27 \pm 0.15 \mathrm{~kg} ; 21 \mathrm{~d}$ ) were distributed based on the bodyweight between 3 treatments with 6 replicates in each treatment including 10 piglets per replicate. The diets corresponding to treatments consisted of a fish meal diet (CON), a fish meal-dried mealworm diet (TM1, 50\% replacement of fish meal with TM meal), and a dried mealworm diet (TM2, 100\% replacement of fish meal with TM meal). This study was performed in two phases as phase 1 ( 0 to 14) and phase 2 (d 15 to 28). The pigs in the TM2 treatment showed a greater gain to feed ratio compared with the TM1 pigs in phase 1. Throughout the experimental period, the average daily gain (ADG) of the TM1 pigs was significantly greater than that of the TM2 treatment. The IgG concentration was increased in the TM1 and TM2 treatments compared with the CON pigs in phase 1. In conclusion, the supplementation of TM meal ( $50 \%$ replacement of fish meal) did not show any adverse effects in the performance of weanling pigs, however, $100 \%$ replacement of fish meal with TM meal is not recommended.
\end{abstract}

Keywords: Insects, Protein source, Immunity, Weanling pigs, Sustainability

\section{INTRODUCTION}

Fish meal and soybean meal are the main protein sources for weanling piglet nutrition. However, their price has been fluctuating due to the increase in the human population and the increase in protein sources demand [1]. Therefore, there is a high demand to detect sustainable alternative protein sources to guarantee the livestock industry. Besides, there is annually a total of 1.3 billion tons of wasted food worldwide, which considers around thirty percent of the total food production for humans [2]. The production of insects from organic refuses seems to be an environmentally friendly procedure to introduce a sustainable high-quality protein source. The insect has already been concerned as an appealing protein 
Acknowledgements Not applicable.

Availability of data and material Upon reasonable request, the datasets of this study can be available from the corresponding author.

Authors' contributions

Conceptualization: Ko HS, Kim YH, Kim JS.

Data curation: Kim JS.

Formal analysis: Ko HS.

Methodology: Kim JS.

Software: Kim JS.

Validation: Kim YH, Kim JS.

Investigation: Ko HS

Writing - original draft: Ko HS, Kim JS.

Writing - review \& editing: Kim YH, Kim JS.

Ethics approval and consent to participate This experiment was aligned to the ethical standards of animal (KW-170519-1) in Institutional Animal Care and Use Committee of Kangwon National University, Chuncheon, Korea. source for the livestock industry due to the nutritional value and sustainability $[3,4]$ but the limited production rate and high cost of production restricted their use in animal diets.

The mass production, rapid life span, and application of organic side streams are the most important features of insects to be used industrially, and in this case, three types of insects including black soldier fly and mealworm have been reported as suitable feed sources [5,6]. Mealworms can be produced from organic wastes, such as expired feeds and food wastes, and the high protein and trace mineral content of mealworms are comparable to the fish meal and soybean meal [7]. Veldkamp et al. [5] reported that the mealworm contained high crude protein and fat which ranges from $44 \%$ to $69 \%$, and $23 \%$ to $47 \%$ respectively. In livestock, several studies reported the dietary mealworm affected positively on growth performance, immunity, and digestibility in pig, broiler, and fish [8-10]. This evidences would suggest that the mealworms can consumed as an alternative high-quality protein feed source regionally or selectively in livestock's diet, and more information about the results using livestock fed mealworm was required for universal use of mealworm as a sustainable protein feed source in responding to food security.

The hypothesis of replacing fish meal with mealworm meal in weanling piglet's diets should be evaluated by comparing the nutritional assessment as well as the functional effects of fish meal, particularly that there is a lack of information on dietary mealworm in weanling piglet. Therefore, this study is designed to evaluate the influence of Tenebrio molitor (TM) meal in diets on the growth rate, immune response, and intestinal integrity in weanling piglet.

\section{MATERIALS AND METHODS}

The experimental design for the current study was permitted by the Committee of Institutional Animal Care and Use of Kangwon National University, Chuncheon 24341, Korea.

\section{Preparation of insect meal}

Defatted TM meal with approximately $6 \%$ crude fat content (as fed) was purchased from a commercial manufacturer (Se-in resource, Anseong, Korea). The TM was fed cereal by-products. The produced larvae were dried by an oven $\left(20 \mathrm{~h}\right.$ at $60^{\circ} \mathrm{C}$ temperature) and ground afterward to prepare the TM meal.

\section{Animals and experimental design}

A total of 180 weanling pigs (Landrace $\times$ Yorkshire $\times$ Duroc) with an average initial bodyweight (BW) of $6.27 \pm 0.15 \mathrm{~kg}$ (age: $21 \mathrm{~d}$ ) were distributed between 3 treatments based on the BW. Each treatment included 6 replicates with 10 piglets per replicate. The diets corresponding to treatments consisted of a fish meal diet (control, CON), a fish meal-dried mealworm diet (TM1, 50\% replacement of fish meal with TM meal), and a dried mealworm diet (TM2, 100\% replacement of fish meal with TM meal). The mash form diets were prepared for pigs in 2 phases including phase 1 (d 0 to14) and phase 2 (d 15 to 28). The diets met the standard of NRC [11] nutrient requirements (Table 1). The pens were equipped with a partially slatted concrete floor $(3.0 \mathrm{~m} \times 3.0 \mathrm{~m})$. The average temperature was adjusted at $30^{\circ} \mathrm{C}$ at the start of the study and was gradually reduced to $25^{\circ} \mathrm{C}$ on $\mathrm{d} 8$ onward. The humidity of the barn was ranged from $65 \%$ to $70 \%$. The infrared heating lamp, low-pressure nipple drinker, and self-feeder were equipped in all the pens to provide constant light and ad libitum access to water and feed.

\section{Experimental sampling}

The BW check was measured for all the pigs at the beginning of the experiment, on day 14 , and day 
Table 1. Ingredient and chemical composition of experimental diets (phase 1, d 0 to 14; phase 2, d 15 to 28) as-fed basis

\begin{tabular}{|c|c|c|c|c|c|c|}
\hline \multirow{2}{*}{ TM (\%) } & \multicolumn{3}{|c|}{ Phase 1} & \multicolumn{3}{|c|}{ Phase 2} \\
\hline & 0 & 2.5 & 5 & 0 & 1.5 & 3 \\
\hline \multicolumn{7}{|l|}{ Ingredients (\%) } \\
\hline Corn & 30.46 & 29.97 & 29.39 & 48.24 & 47.9 & 47.55 \\
\hline SBM (45\%) & 18.2 & 18.1 & 18.1 & 21.1 & 21.1 & 21.1 \\
\hline TM meal & - & 2.5 & 5 & - & 1.5 & 3 \\
\hline Fish meal & 5 & 2.5 & - & 3 & 1.5 & - \\
\hline Whey powder & 15 & 15 & 15 & 10 & 10 & 10 \\
\hline Lactose & 12 & 12 & 12 & 6 & 6 & 6 \\
\hline SDPP & 5 & 5 & 5 & 2 & 2 & 2 \\
\hline Sugar & 6 & 6 & 6 & 4 & 4 & 4 \\
\hline Soy oil & 5.58 & 5.57 & 5.56 & 2.3 & 2.3 & 2.29 \\
\hline Lys (78\%) & 0.08 & 0.13 & 0.17 & 0.13 & 0.15 & 0.18 \\
\hline Met $(100 \%)$ & 0.05 & 0.07 & 0.08 & 0.06 & 0.06 & 0.07 \\
\hline $\operatorname{Trp}(10 \%)$ & 0.45 & 0.52 & 0.59 & 0.42 & 0.47 & 0.51 \\
\hline Limestone & 1.1 & 1.1 & 1.1 & 1.1 & 1.1 & 1.1 \\
\hline MCP & 0.34 & 0.75 & 1.16 & 0.77 & 1.01 & 1.26 \\
\hline Salt & 0.11 & 0.16 & 0.22 & 0.25 & 0.28 & 0.31 \\
\hline $\mathrm{ZnO}$ & 0.3 & 0.3 & 0.3 & 0.3 & 0.3 & 0.3 \\
\hline Vitamin premix ${ }^{1)}$ & 0.11 & 0.11 & 0.11 & 0.11 & 0.11 & 0.11 \\
\hline Mineral premix ${ }^{2}$ & 0.22 & 0.22 & 0.22 & 0.22 & 0.22 & 0.22 \\
\hline Total & 100 & 100 & 100 & 100 & 100 & 100 \\
\hline \multicolumn{7}{|c|}{ Chemical composition (\%) } \\
\hline ME (kcal/kg) & 3,490 & 3,490 & 3,490 & 3,350 & 3,350 & 3,350 \\
\hline $\mathrm{CP}$ & 21.01 & 20.98 & 20.99 & 19.01 & 19.01 & 19.02 \\
\hline $\mathrm{Ca}$ & 0.85 & 0.85 & 0.85 & 0.85 & 0.85 & 0.85 \\
\hline Total P & 0.61 & 0.65 & 0.7 & 0.68 & 0.71 & 0.74 \\
\hline Lysine & 1.4 & 1.4 & 1.4 & 1.2 & 1.2 & 1.2 \\
\hline Met + Cys & 0.82 & 0.82 & 0.82 & 0.71 & 0.71 & 0.71 \\
\hline
\end{tabular}

${ }^{1)}$ Supplied per kg diet: 9,600 IU vitamin A, 1,800 IU vitamin $D_{3}, 24 \mathrm{mg}$ vitamin $\mathrm{E}, 1.5 \mathrm{mg}$ vitamin $\mathrm{B}_{1}, 12 \mathrm{mg}$ vitamin $\mathrm{B}_{2}, 2.4 \mathrm{mg}$ vitamin $\mathrm{B}_{6}, 0.045 \mathrm{mg}$ vitamin $\mathrm{B}_{12}, 1.5 \mathrm{mg}$ vitamin $\mathrm{K}_{3}, 24 \mathrm{mg}$ pantothenic acid, $45 \mathrm{mg}$ niacin, $0.09 \mathrm{mg}$ biotin, $0.75 \mathrm{mg}$ folic acid, 18 mg ethoxyquin.

${ }^{2)}$ Supplied per kg diet: 162 mg Fe, 96 mg Cu, 72 mg Zn, 46.49 mg Mn, 0.9 mg I, 0.9 mg Co, 0.3 mg Se.

TM, Tenebrio molitor larvae; SBM, soybean meal; SDPP, spray-dried porcine plasma; Lys, L-Lysine; Met, DL-Methionine; Trp, L-Tryptophan; MCP, monocalcium phosphate; ME, metabolizable energy; CP, crude protein; Cys, L-cystine.

28. Feed intake (ADFI), gain to feed ratio (G:F), and average daily gain (ADG) were measured at the end of each phase. The calculation of $\mathrm{ADFI}$ and $\mathrm{ADG}$ was performed by dividing the $\mathrm{BW}$ and ADFI of the pens by the number of animal days (considering the BW and ADFI of the mortalities). The chromium oxide $(2.5 \mathrm{~g} / \mathrm{kg})$ was used as an inert marker and mixed with the diets during the last six days in each phase for the measurement of apparent total tract digestibility (ATTD) of nutrients. A $100 \mathrm{~g}$ fecal sample was taken in the last 3 days in each phase, from each of the four selected pigs with a BW around the average BW of the cage. An air forced oven was applied to dry the pooled fecal samples for $72 \mathrm{~h}$ at $60^{\circ} \mathrm{C}$ and ground by a mill (Thomas Model 4 Wiley ${ }^{\circledR}$ Mill, Thomas Scientific, Swedesboro, NJ, USA) equipped with a 1-mm screen to prepare the final samples to be used for chemical analysis. Two pigs around the average weight of the pen were selected 
for blood sampling (jugular vein) using Becton Dickinson anticoagulants-free disposable vacutainer tube (Franklin, NJ, USA). The serum samples were divided after centrifugation for $15 \mathrm{~min}(3,000 \times \mathrm{g}$ at $4{ }^{\circ} \mathrm{C}$ ) and kept at $-20^{\circ} \mathrm{C}$ to be stored for the analysis of hematological parameters. Two piglets per cage (around the average BW) were selected to evaluate the treatment effects on small intestinal morphology. The selected pigs were euthanized by electrocution at $\mathrm{d} 28$ and the collected samples from the duodenum, jejunum and ileum of the small intestine were cleaned and washed by physiological saline. After the throughout washing, a fixative solution including $20 \mathrm{~g} / \mathrm{L}$ paraformaldehyde, $15 \mathrm{~g} / \mathrm{L}$ acrolein, and $30 \mathrm{~g} / \mathrm{L}$ glutaraldehyde was used for submerging the samples at $\mathrm{pH} 7.3(0.1 \mathrm{M}$ collidine buffer), and then the final samples were used for the morphological integrity evaluation.

\section{Chemical and immunological analyses}

The analysis of fece and diet samples were evaluated in triplicate for crude protein $(\mathrm{CP}$, method 990.03; AOAC [12]) and dry matter (DM, method 930.15; AOAC [12]). The bomb calorimeter (Model1261, Parr Instrument, Moline, IL, USA) was used for the measurement of gross energy (GE) of feces and diets, and a spectrophotometer (Jasco V-650, Tokyo, Japan) was applied to determine the chromium concentration. The blood samples were analyzed by Hemavet ${ }^{\circledR}$ Hematology System (Drew Scientific, Oxford, CT) to determine the concentrations of leukocytes including white blood cells (WBC), lymphocytes, red blood cells $(\mathrm{RBC})$, and monocytes. Immunoglobin $\mathrm{G}(\mathrm{Ig} G)$, IL-1 $\beta$, TNF- $\alpha$, and IL-6 were evaluated using ELISA kit (Cusabio Biotech, Wuhan, China).

Table 2. Analyzed nutrient composition (as-fed basis) of Tenebrio molitor larvae

\begin{tabular}{|c|c|}
\hline Items & Tenebrio molitor larvae \\
\hline Dry matter (\%) & 96.25 \\
\hline Gross energy (kcal/kg) & $4,666.95$ \\
\hline Crude protein (\%) & 71.36 \\
\hline Ether extract (\%) & 5.20 \\
\hline $\mathrm{Ca}(\%)$ & 3.81 \\
\hline $\mathrm{P}(\%)$ & 0.43 \\
\hline \multicolumn{2}{|l|}{ Essential amino acids (\%) } \\
\hline Arginine & 1.37 \\
\hline Histidine & 1.18 \\
\hline Isoleucine & 2.07 \\
\hline Leucine & 3.82 \\
\hline Lysine & 2.49 \\
\hline Methionine & 0.79 \\
\hline Phenylalanine & 0.84 \\
\hline Threonine & 1.15 \\
\hline Valine & 1.57 \\
\hline \multicolumn{2}{|l|}{ Non-essential amino acid (\%) } \\
\hline Alanine & 3.12 \\
\hline Asparagine & 1.88 \\
\hline Cysteine & 0.31 \\
\hline Glutamine & 10.12 \\
\hline Glycine & 3.62 \\
\hline Proline & 1.88 \\
\hline Serine & 2.02 \\
\hline Tyrosine & 3.52 \\
\hline
\end{tabular}




\section{Small intestinal morphology}

The histomorphological evaluation in different sections of intestine including jejunum, duodenum, and ileum was performed as the method suggested by Hosseindoust et al. [13]. In short, azure A and eosin were applied for the cross-sections of jejunum, duodenum, and ileum by standard dehydration procedure through paraffin embedation. A total of ten crypt-villus units in triplicate were used for intestinal cross-sections samples. The villus height (VH) and Crypt depth (CD) were determined from the tip of the villi to the crypt junction and the depth of the invagination between adjacent villi, respectively. An image processing system (Optimus software version 6.5) was used for all intestinal morphological parameters (Media Cybergenetics, North Reading, MA, USA).

\section{Statistical analysis}

In this trial, results were analyzed using the GLM procedure (SAS Institute, Cary, NC, USA). The significant statistical differences were evaluated among the treatments, and were divided by Tukey's HSD tests. For growth rate, the pen was considered as an experimental unit. The mean of two pigs was considered as an experimental unit for the analysis of nutrient digestibility, blood parameters, and intestinal integrity. The $\alpha$ level of statistical significance was 0.05 .

\section{RESULTS}

\section{Growth performance}

The weanling pigs were healthy and no signs of illness were detected during the whole experiment, and there was no mortality in all the treatments. The result of the growth rate of the weanling pigs is shown in Table 3. Replacing a fish meal with dried mealworm did not affect the ADG and ADFI of weanling pigs $(p>0.05)$ at phase 1 . However, pigs in the TM2 treatment showed a greater G:F ratio compared with the TM1 pigs $(p<0.05)$. At phase 2, there was no significant difference between three dietary treatments. Throughout the experimental period, ADG of the TM1 pigs was greater than that of the TM2 treatment $(p<0.05)$.

Table 3. Effects of dried Tenebrio molitor larvae supplementation replacing fish meal in the diet on growth performance of weanling pigs ${ }^{1)}$

\begin{tabular}{lccccc}
\hline \multicolumn{1}{c}{ Items } & CON & TM1 & TM2 & SEM & $p$-value \\
\hline Phase 1 (d 0-14) & & & & & \\
ADG (g/d) & 244 & 256 & 241 & 4.92 & 0.095 \\
ADFI (g/d) & 368 & 376 & 368 & 7.73 & 0.676 \\
G:F & $0.66^{\text {ab }}$ & $0.68^{\mathrm{a}}$ & $0.65^{\mathrm{b}}$ & 0.06 & 0.024 \\
Phase 2 (d 15-28) & & & & & \\
ADG (g/d) & 436 & 442 & 417 & 7.19 & 0.069 \\
ADFI (g/d) & 715 & 711 & 676 & 16.06 & 0.211 \\
G:F & 0.61 & 0.62 & 0.62 & 0.15 & 0.814 \\
Overall (d 0-28) & & & & & \\
ADG (g/d) & $340^{\mathrm{ab}}$ & $349^{\mathrm{a}}$ & $329^{\mathrm{b}}$ & 3.98 & 0.010 \\
ADFI (g/d) & 541 & 543 & 522 & 7.92 & 0.149 \\
G:F & 0.63 & 0.64 & 0.63 & 0.12 & 0.644 \\
\hline
\end{tabular}

1)Data represent means based on six replicates per treatment.

CON, control; TM, Tenebrio molitor larvae; SEM, standard error of mean; ADG, average daily gain; ADFI, average daily feed intake; G:F, gain and feed intake ratio. 


\section{Nutrient digestibility}

The nutrient digestibility and fecal score results are presented in Table 4. The ATTD of GE, DM, and $\mathrm{CP}$ did not change by the treatments. However, a numerical increase was detected in the TM1 treatment for the ATTD of DM $(p=0.081)$ and GE $(p=0.078)$ during the first phase.

\section{Blood characteristics}

The WBC, RBC, lymphocyte, and monocyte were not affected (Table 5). However, the IgG concentration was increased in the TM1 and TM2 in phase 1 compared to treatment $1(p<0.05)$.

\section{Cytokine secretion}

The cytokine secretion of serum is shown in Table 6. No significant differences were detected in the secretion of serum cytokine among the dietary treatments. However, the secretion of IL-6 was numerically lower $(p=0.052)$ in the TM1 than in the CON and TM2.

Table 4. Effects of dried Tenebrio molitor larvae supplementation replacing fish meal in the diet on nutrients digestibility and fecal scores ${ }^{1)}$ of weanling pigs ${ }^{2)}$

\begin{tabular}{lrrrrr}
\hline \multicolumn{1}{c}{ Items } & CON & TM1 & TM2 & SEM & $p$-value \\
\hline Phase 1 (d 14) & & & & & \\
DM & 85.51 & 87.03 & 85.80 & 0.47 & 0.081 \\
GE & 84.57 & 86.57 & 84.94 & 0.61 & 0.078 \\
CP & 83.07 & 83.26 & 82.28 & 0.35 & 0.146 \\
Fecal score & 2.64 & 2.61 & 2.28 & 0.25 & 0.530 \\
Phase 2 (d 28) & & & & & \\
DM & 87.11 & 86.15 & 87.43 & 0.52 & 0.226 \\
GE & 83.44 & 83.08 & 82.45 & 0.63 & 0.549 \\
CP & 81.46 & 81.87 & 81.38 & 0.99 & 0.933 \\
\hline
\end{tabular}

${ }^{1)}$ Fecal scores: 1 , hard feces; 2 , slightly soft feces; 3 , soft and partially-formed feces; 4 , loose and semiliquid feces; 5 , watery feces.

${ }^{2)}$ Data represent means based on six replicates per treatment.

CON, control; TM, Tenebrio molitor larvae; SEM, standard error of mean; DM, dry matter; GE, gross energy; CP, crude protein.

Table 5. Effects of dried Tenebrio molitor larvae supplementation replacing fish meal in diet on hematological traits of weanling pigs ${ }^{11}$

\begin{tabular}{lrrrrr}
\hline \multicolumn{1}{c}{ Items } & CON & TM1 & TM2 & SEM & $p$-value \\
\hline Phase 1 (d 14) & & & & & \\
WBC (10 $/ \mathrm{uL})$ & 19.26 & 19.83 & 19.43 & 1.32 & 0.831 \\
RBC (10\%/uL) & 6.26 & 6.01 & 6.22 & 0.15 & 0.453 \\
Lymphocyte (\%) & 55.27 & 56.62 & 61.06 & 2.01 & 0.138 \\
Monocyte (\%) & 4.92 & 4.87 & 4.83 & 0.48 & 0.992 \\
IgG (ng/mL) & $10.85^{\mathrm{b}}$ & $17.75^{\mathrm{a}}$ & $14.95^{\mathrm{a}}$ & 1.79 & 0.048 \\
Phase 2 (d 28) & & & & & \\
WBC (103/uL) & 21.28 & 20.32 & 21.21 & 1.68 & 0.469 \\
RBC (10\%/uL) & 6.55 & 6.60 & 6.11 & 0.17 & 0.122 \\
Lymphocyte (\%) & 58.30 & 60.25 & 57.68 & 4.33 & 0.909 \\
Monocyte (\%) & 4.45 & 4.35 & 5.93 & 0.52 & 0.085 \\
IgG (ng/mL) & 18.37 & 25.70 & 26.86 & 3.82 & 0.264 \\
\hline
\end{tabular}

${ }^{1)}$ Data represent means based on six replicates per treatment.

CON, control; TM, Tenebrio molitor larvae; SEM, standard error of mean; WBC, white blood cells; RBC, red blood cells; IgG, immunoglobulin G. 


\section{Gut morphometric analysis}

The result of the gut integrity analysis is shown in Table 7. No significant difference was observed in the $\mathrm{VH}$ and $\mathrm{CD}$ of the small intestine between the three treatments.

\section{DISCUSSION}

The insect meal is now being considered as important protein sources in animal nutrition [5]. Some researchers demonstrated that insect-derived meals have a good potential to be an alternative to fish meal in feeds for animal farming [8,14]. Our results also showed the beneficial effects of replacing fish meal with dried mealworms in weanling pigs. Results of the growth trial indicated that dried mealworm can be replaced at a $50 \%$ level of the fish meal in the diet of weanling pig, without any adverse influences on average daily gain. However, the total replacement of fish meal with dried TM meal slightly reduced ADG of weanling pigs. The improved ADG and G:F in the TM1 might be due to the more balanced amino acid composition compared with TM2. However, there are few studies on the influences of TM meal in diet of pigs, using the other high-protein insect

Table 6. Effects of dried Tenebrio molitor larvae supplementation replacing fish meal in the diet on immune response and fecal score of weanling pigs ${ }^{1)}$

\begin{tabular}{crrrrr}
\hline Items & CON & TM1 & TM2 & SEM & $p$-value \\
\hline Phase 1 $(\mathrm{d} 14)$ & & & & & \\
IL-1 $\beta$ (pg/mL) & 14.10 & 14.27 & 14.23 & 0.64 & 0.980 \\
TNF- $\alpha(\mathrm{pg} / \mathrm{mL})$ & 123.14 & 112.85 & 121.79 & 14.08 & 0.855 \\
IL-6 (pg/mL) & 5.05 & 2.34 & 3.94 & 0.72 & 0.052 \\
Phase 2 (d 28) & & & & & \\
IL-1 $\beta$ (pg/mL) & 10.53 & 9.30 & 10.29 & 2.08 & 0.906 \\
TNF- $\alpha(\mathrm{pg} / \mathrm{mL})$ & 161.36 & 140.20 & 150.49 & 14.82 & 0.611 \\
IL-6 (pg/mL) & 3.35 & 2.63 & 3.47 & 0.91 & 0.782 \\
\hline
\end{tabular}

${ }^{1)}$ Data represent means based on six replicates per treatment.

CON, control; TM, Tenebrio molitor larvae; SEM, standard error of mean; IL, interleukin; TNF, tumor necrosis factor.

Table 7. Effects of dried Tenebrio molitor larvae supplementation replacing fish meal in the diet on small intestinal morphology of weanling pigs ${ }^{1)}$

\begin{tabular}{lccccc}
\hline \multicolumn{1}{c}{ Items } & CON & TM1 & TM2 & SEM & $p$-value \\
\hline $\begin{array}{l}\text { Villus height }(\mu \mathrm{m}) \\
\text { Duodenum }\end{array}$ & 584 & 579 & 578 & 13.23 & 0.952 \\
$\quad$ Jejunum & 521 & 541 & 539 & 18.50 & 0.718 \\
$\quad$ Ileum & 445 & 426 & 467 & 19.34 & 0.350 \\
Crypt depth $(\mu \mathrm{m})$ & & & & & \\
$\quad$ Duodenum & 324 & 317 & 330 & 14.47 & 0.816 \\
Jejunum & 330 & 355 & 349 & 14.64 & 0.473 \\
Ileum & 265 & 270 & 268 & 12.63 & 0.964 \\
VH/CD & & & & & \\
$\quad$ Duodenum & 1.82 & 1.86 & 1.76 & 0.10 & 0.783 \\
Jejunum & 1.64 & 1.53 & 1.55 & 0.11 & 0.788 \\
Ileum & 1.73 & 1.58 & 1.74 & 0.07 & 0.270 \\
\hline
\end{tabular}

${ }^{1)}$ Data represent means based on six replicates per treatment.

CON, control; TM, Tenebrio molitor larvae; SEM, standard error of mean; VH/CD, villus height and crypt depth ratio. 
meals in pigs and other species diets have been reported by several studies [15]. Jin et al. [8] found that increasing the level of mealworms meal to $6 \%$ in diets linearly improved ADG and G:F of weanling pig.

In the present study, the supplementation of dried mealworms had no effect in the digestibility of nutrients in the piglet. In accordance with the previous report of Biasato et al. [16], who reported that the dietary insect meal did not affect the nutrient digestibility of piglet. On the other hand, Jin et al. [8] reported that the inclusion of dried mealworm in diets improved the digestibility of nutrients. There is a close correlation between nutrient digestibility and diet composition. Therefore, these discrepancies may be responded by the variation in the source of insects, dietary inclusion, and processing methods.

The insignificant hematological parameters result in weanling pigs fed TM is in accordance with the report of Biasato et al. [16] who reported no significant response on the blood profile of weaned piglet fed insect meal. However, immunoglobulin $\mathrm{G}(\mathrm{IgG})$ was influenced by the dried mealworm containing diets. In contrast Jin et al. [8] showed no significant effect in serum IgG concentration when $6 \%$ of mealworm was supplemented in the diet. It is well known that the chitin content of commercially farmed insect meals is high and can include from 11.6 to $137.2 \mathrm{~g} /$ ton of the meal [17]. Chitin has been known as an immune system stimulator [17], and its effects may appear as increased blood IgG. In this study, the replacement of fish meal by dried meal up to $5 \%$ did not affect the serum cytokines concentrations in weaned pigs. However, the IL-6 concentration tended to be decreased with the supplementation of dried mealworm in phase 1 . Similarly, it was reported that dietary supplementation of Hermetia illucens larvae decreased mRNA expression of inflammatory cytokines [18].

Dietary dried mealworms inclusion showed no effect in the gut integrity of the weaned pigs in this trial, which is consistent with published reports including insect meal in animal diet $[10,19]$. Biasato et al. [16] reported that no effect on the gut integrity of weanling pigs fed insect meal. In a previous study, Hosseindoust et al. [20] reported that the intestinal structure integrity is associated with the maintenance of intestinal nutrition. Dietary inclusion of dried mealworms did not influence the intestinal morphology, it can be hypothesized that the supplementation of insect meal does not have any adverse influence on gut integration or nutrient absorption.

\section{CONCLUSION}

Dietary supplementation of dried TM meal (50\% replacement of fish meal) showed no adverse influence on the growth performance, blood parameters, thus it can partially be considered as an alternative protein source to fish meal.

\section{REFERENCES}

1. Bosch G, Zhang S, Oonincx DGAB, Hendriks WH. Protein quality of insects as potential ingredients for dog and cat foods. J Nutr Sci. 2014;3:e29.

2. Gustafsson J, Cederberg C, Sonesson U. Global food losses and food waste-extent, causes and prevention. Rome: Food and Agriculture Organization of the United Nations. 2011.

3. Gjerris M, Gamborg C, Röcklinsberg H. Ethical aspects of insect production for food and feed.J Insects Food Feed. 2016; 2:101-10.

4. Dobermann D, Swift JA, Field LM. Opportunities and hurdles of edible insects for food and feed. Nutr Bull. 2017; 42:293-308.

5. Veldkamp T, Van Duinkerken G, van Huis A, Lakemond CMM, Ottevanger E, Bosch G, et 
al. Insects as a sustainable feed ingredient in pig and poultry diets: a feasibility study [Internet]. Wageningen UR Livestock Research. 2012. https://www.wur.nl/upload_mm/2/8/0/f26765b998b2-49a7-ae43-5251c5b694f6_234247\%5B1\%5D. Accessed 20 Jan 2020.

6. Veldkamp T, Bosch G. Insects: a protein-rich feed ingredient in pig and poultry diets. Animal Front. 2015;5:45-50.

7. Bosch G, Veenenbos ME, van Zanten HHE, Meijer NP, van der Fels-Klerx HJ, van Loon JJA. Efficiency of organic stream conversion by black soldier fly larvae: a review of the scientific literature. J Insects Food Feed. 2018;4 Suppl 1:S44.

8. Jin XH, Heo PS, Hong JS, Kim NJ, Kim YY. Supplementation of dried mealworm (Tenebrio molitor larva) on growth performance, nutrient digestibility and blood profiles in weaning pigs. Asian-Australas J Anim Sci. 2016;29:979-86.

9. Bovera F, Piccolo G, Gasco L, Marono S, Loponte R, Vassalotti G, et al. Yellow mealworm larvae (Tenebrio molitor, L.) as a possible alternative to soybean meal in broiler diets. Br Poult Sci. 2015;56:569-75.

10. Biasato I, Gasco L, De Marco M, Renna M, Rotolo L, Dabbou S, et al. Effects of yellow mealworm larvae (Tenebrio molitor) inclusion in diets for female broiler chickens: implications for animal health and gut histology. Anim Feed Sci Tech. 2017;234:253-63.

11. NRC [National Research Council]. Nutrient requirements of swine. 11th ed. Washington, DC: National Academies Press; 2012.

12. AOAC [Association of Official Analytical Chemists] International. Official methods of analysis of AOAC International. 18th ed. Gaithersburg, MD: AOAC International; 2007.

13. Hosseindoust AR, Lee SH, Kim JS, Choi YH, Kwon IK, Chae BJ. Productive performance of weanling piglets was improved by administration of a mixture of bacteriophages, targeted to control Coliforms and Clostridium spp. shedding in a challenging environment. J Anim Physiol Anim Nutr. 2017;101:e98-107.

14. De Marco M, Martínez S, Hernandez F, Madrid J, Gai F, Rotolo L, et al. Nutritional value of two insect larval meals (Tenebrio molitor and Hermetia illucens) for broiler chickens: apparent nutrient digestibility, apparent ileal amino acid digestibility and apparent metabolizable energy. Anim Feed Sci Tech. 2015;209:211-8.

15. Yoo JS, Cho KH, Hong JS, Jang HS, Chung YH, Kwon GT, et al. Nutrient ileal digestibility evaluation of dried mealworm (Tenebrio molitor) larvae compared to three animal protein by-products in growing pigs. Asian-Australas J Anim Sci. 2019;32:387-94.

16. Biasato I, Renna M, Gai F, Dabbou S, Meneguz M, Perona G, et al. Partially defatted black soldier fly larva meal inclusion in piglet diets: effects on the growth performance, nutrient digestibility, blood profile, gut morphology and histological features. J Anim Sci Biotechnol. 2019;10:12.

17. Finke MD. Estimate of chitin in raw whole insects. Zoo Biol. 2007;26:105-15.

18. Yu M, Li Z, Chen W, Rong T, Wang G, Ma X. Hermetia illucens larvae as a potential dietary protein source altered the microbiota and modulated mucosal immune status in the colon of finishing pigs.J Anim Sci Biotechnol. 2019;10:50.

19. Spranghers T, Michiels J, Vrancx J, Ovyn A, Eeckhout M, De Clercq P, et al. Gut antimicrobial effects and nutritional value of black soldier fly (Hermetia illucens L.) prepupae for weaned piglets. Anim Feed Sci Tech. 2018;235:33-42.

20. Hosseindoust AR, Lee SH, Kim JS, Choi YH, Noh HS, Lee JH, et al. Dietary bacteriophages as an alternative for zinc oxide or organic acids to control diarrhea and improve the performance of weanling piglets. Vet Med Czech. 2017;62:53-61. 